\title{
Postmarketing surveillance of the safety of cimetidine: 10 year mortality report
}

\author{
D G Colin-Jones, M J S Langman, D H Lawson, R F A Logan, K R Paterson, M P Vessey
}

\begin{abstract}
A total of 9928 cimetidine users were identified from prescriptions in four centres and followed for 10 years. The 'all-cause' mortality ratio fell from 1.9 in year 1 to 1.0 in years 8 to 10 . Most of the early excess in mortality was attributable to cimetidine being given in the late stages of many diseases, often to counter adverse gastric effects of other drugs. Specific causes of mortality during years 5-10 of the study, were generally unremarkable. Significant increases in mortality ratios were apparent, however, for oesophageal cancer (years $5-7,2 \cdot 3$; years 8$10,1.9)$; lung cancer (years $5-7,1 \cdot 1$; years $8-$ $10,1.7)$; diseases of the oesophagus, stomach, and duodenum (years 5-7, 3.3; years 8-10, 2.3); and chronic liver disease (years 5-7, 2.4; years 8-10, 3.3). None of these increases in mortality seems to be attributable to an adverse effect of cimetidine use. Data are also presented for mortality from diseases of the nervous system. Eight deaths (of which one was miscoded) were certified as being from motor neurone disease, representing a mortality ratio of 2.6 for years 2-10 of the study which is of borderline statistical significance. This study confirms that cimetidine is safe. Mortality from some diseases increased over the study period, but selection rather than any adverse effect of the drug is likely to be the explanation.

(Gut 1992; 33: 1280-1284)
\end{abstract}

Hospital, Portsmouth

D G Colin-Jones

Queen Elizabeth Hospital, Birmingham M J S Langman

Royal Infirmary, Glasgow, and Úniversity of Strathclyde D H Lawson

University Hospital, Nottingham R F A Logan

Royal Infirmary, Glasgow K R Paterson

Department of Public Health and Primary Care, Gibson Building, Radcliffe Infirmary, Oxford OX2 6HE M P Vessey

Correspondence to: Professor M P Vessey. Accepted for publication 20 December 1991

Our postmarketing surveillance study of the safety of cimetidine has already been described in earlier published reports on gastric cancer, ${ }^{1-2}$ mortality, ${ }^{3-4}$ and morbidity. ${ }^{5}$ The earlier reports should be consulted for details of subjects who died during the first four years of the study. ${ }^{1-4}$ We present here information about deaths that occurred during the subsequent six years and, in addition, complete mortality data to show the overall patterns.

\section{Methods}

The investigation was carried out in four centres - Glasgow, Nottingham, Oxford, and Portsmouth. A total of 9928 people who had taken cimetidine were identified between 1977 and early 1980 by means of copies of prescriptions supplied by the Prescription Pricing Bureau three centres). At the end of the first year of follow up, the surviving members of the original cohort were flagged in the National Health Service Central Registers at Southport and Edinburgh. Copies of death certificates with the underlying cause of death (UCD) already coded were sent to the monitoring centre (Oxford), usually within six months of death. Three centres (Nottingham, Oxford, and Portsmouth) retrieved general practitioner (GP) medical records for deceased patients and all centres had access to hospital records and post mortem reports when necessary. These records do not always provide accurate information on drugs prescribed but we were usually able to establish an approximate usage of cimetidine for each deceased subject during each quarter of each year. We also recorded clinical details for conditions in which we were particularly interested. We examined the data on cimetidine use in many ways, looking for differing mortality patterns in short and long term users and for possible associations between use of the drug and the terminal illness. We also recorded whether or not the patient had used ranitidine or other antisecretory drugs. Drug use information for deceased subjects was supported by the results of a questionnaire survey of the GPs responsible for the care of a $10 \%$ sample of the surviving cohort; the purpose was to obtain a simple assessment of the general pattern of the use of cimetidine, ranitidine, and certain other drugs used for dyspeptic symptoms during each quarter of 1987. (Nottingham) or by local pharmacists (the other
Mortality was examined according to sex, age, UCD, study year, and centre. Expected deaths were estimated from Office of Population Censuses and Surveys (OPCS) mortality statistics for England and Wales during 1979 to 1987. In 1984, which covered some deaths in study years $4,5,6$, and 7 because recruitment was staggered, the OPCS introduced changes in the criteria for determining the UCD. In effect, these changes reduce the number of deaths from bronchopneumonia (conversion factor $2 \cdot 2$ ) and certain other non-specific illnesses and increases the number of deaths from some other diseases (for example endocrine diseases, mental disorders, and musculoskeletal disorders) in these and following years. Accordingly, the results for study years 5-10 are not strictly comparable with those described for previous years, although in practice the differences, apart from bronchopneumonia, are very small. In 1985, the OPCS 
TABLE I Observed deaths ( 0$)$ from all causes and observed deaths divided by deaths expected $(O / E)$ at rates for England and Wales ${ }^{\star}$ in each centre in three year groupings

\begin{tabular}{|c|c|c|c|c|c|c|}
\hline \multirow[t]{2}{*}{ Centre } & & \multicolumn{5}{|c|}{ Study years } \\
\hline & & 1 & $2-4$ & $5-7$ & $8-10$ & $2-10$ \\
\hline Glasgow & $\mathrm{O}$ & 59 & 129 & 138 & 139 & 406 \\
\hline \multirow[t]{2}{*}{ Nottingham } & $\begin{array}{l}\mathrm{O} / \mathrm{E} \\
\mathrm{O}\end{array}$ & 65 & $146^{1 \cdot 1}$ & $9^{1 \cdot 3}$ & $116^{\frac{1 \cdot 2}{2}}$ & $361^{1 \cdot 2}$ \\
\hline & $\mathrm{O} / \mathrm{E}$ & $1 \cdot 6$ & $1 \cdot 3$ & 0.9 & $1 \cdot 0$ & $1 \cdot 1$ \\
\hline \multirow[t]{2}{*}{ Oxford } & $\mathrm{O}$ & 123 & 190 & 175 & 143 & 508 \\
\hline & $\mathrm{O} / \mathrm{E}$ & $2 \cdot 0$ & $1 \cdot 2$ & $1 \cdot 1$ & 0.9 & $1 \cdot 1$ \\
\hline Portsmouth & $\mathrm{O}$ & 138 & 224 & 200 & 154 & 578 \\
\hline \multirow[t]{2}{*}{ Total } & O & 385 & 689 & $612^{3}$ & 552 & $1853^{2}$ \\
\hline & $\mathrm{O} / \mathrm{E}$ & 1.9 & $1 \cdot 3$ & $1 \cdot 2$ & 1.0 & $1 \cdot 2$ \\
\hline
\end{tabular}

^ OPCS Mortality Statistics for England and Wales, Series DH2 Nos 6-14, 1979-87 and appropriate study populations, male and female in 5 year increments.

published information relating to all diseases mentioned on the death certificate and we were able to compare this information with corresponding study data as well.

\section{Subjects}

Altogether 9377 subjects (5890 men, mean age 50.8 years: 3487 women, mean age 56.5 years) were identified and flagged at the NHS Central Registers at the end of the first year of follow up. Since the publication of our second, third and fourth year mortality report, ${ }^{4}$ a further 25 deaths have been identified in those years, including 10 among patients previously lost to follow up. Thus, the cohort at the start of the fifth year was reduced to 8698 (63\% male, mean age $52 \cdot 4$ years: $37 \%$ female, mean age 58.3 years). At the end of the 10th year there were 7534 survivors. The ratio of men to women has remained constant throughout the study. The data are complete to 31 March 1991.

\section{Results}

Table I shows the total numbers of deaths recorded at each centre and overall, and the ratio of observed to expected numbers calculated on a national basis, making allowance for age, sex, and calendar year. We have reported previously that most of the large excess of deaths that occurred in the first years of the study reflects the use of cimetidine for various reasons during terminal illness. ${ }^{3-4}$ Accordingly, reduction in the ratios over the succeeding years was expected. Nonetheless, the numbers of deaths in Glasgow and Portsmouth remain slightly higher than expected, even after many years of follow up.

The numbers of deaths for all centres combined, by underlying cause in the main chapters of the International Classification of Diseases (ICD: 9th revision), are given in Table II. Apart from diseases of the digestive system, the observed to expected ratios are not consistently high in any chapter, although there are a number of statistically significant findings in year 1 and in years 2-4 which have been discussed in a previous report. ${ }^{4}$

We also examined each disease within every chapter and give, in Table III, the results for diseases we described individually in our last mortality report. ${ }^{+}$Considering years $5-10$, the findings for most of the diseases are unremarkable and require no further discussion. Statistically significant increases in risk remain, however, for oesophageal cancer; cancer of the trachea, bronchus, and lung; diseases of the oesophagus, stomach, and duodenum, including gastrointestinal bleeding; and chronic liver disease and cirrhosis. In addition, there were some interesting findings with regard to pancreatitis and diseases of the nervous system (not shown in the Table - see below). As the data for year 1 are difficult to interpret because cimetidine was being used in the terminal stages of many diseases, the following paragraphs give brief clinical details for deaths occurring in years 2-10 only.

\section{CANCER OF THE OESOPHAGUS, CANCER OF THE STOMACH (ICD I 5O-I 5I)}

(Years 2-10-oesophageal cancer: male obs 16, exp 9.1: female obs 10, exp 4.0; stomach cancer: male obs 35, $\exp 21 \cdot 6$ : female obs 14, $\exp 9 \cdot 0$ )

We reviewed these deaths in a recent paper. ${ }^{2}$ Detailed examination of the records was possible for all but four of the patients but did not show anything unusual; in particular, the pattern of use of cimetidine was no different from that in patients dying from other causes (excluding digestive diseases). Six patients were diagnosed as having malignancy before treatment with cimetidine and six had stopped treatment at least five years before diagnosis of the tumour. Both sexes show an observed to expected ratio above unity for both cancers. Proved gastric ulcer and non-specific complaints were reported as initial indications for treatment with cimetidine more frequently in the stomach cancer group than in the remainder of the cohort where duodenal ulcer predominated.

CANCER OF THE TRACHEA, BRONCHUS, AND LUNG (ICD I62)

(Years 2-10-male obs 151, $\exp 95:$ female obs 25, $\exp 22)$

Apart from years 5 to 7 , we continue to record high observed to expected ratios of lung cancer deaths among our male subjects under 70 years of age, mainly in the 50-59 age group. There was no difference in the amount of cimetidine taken by patients who died of lung cancer and those who died from other non-digestive tract diseases. Of the 176 who died from lung cancer, at least 141 were smokers and others for whom the relevant information was not recorded in the case notes may also have smoked.

DISEASES OF THE OESOPHAGUS, STOMACH, AND DUODENUM INCLUDING GASTROINTESTINAL BLEEDING (ICD 530-537, 578)

(Years 2-10-male obs 31, $\exp 9 \cdot 4$ : female obs 28, $\exp 7 \cdot 6)$

The 59 deaths involved the oesophagus (11), stomach (16), duodenum (22), unspecified 
TABLE II Observed numbers of deaths $(0)$ and observed to expected $(O / E)$ ratios for individual ICD chapters

\begin{tabular}{|c|c|c|c|c|c|c|}
\hline \multirow[t]{2}{*}{ ICD chapter } & & \multicolumn{5}{|c|}{ Study years } \\
\hline & & 1 & $2-4$ & $5-7$ & $8-10$ & $2-10$ \\
\hline 001-139 & $\mathrm{O}$ & 1 & 3 & 4 & 2 & 9 \\
\hline Infectious \& parasitic diseases & $\mathrm{O} / \mathrm{E}$ & $1 \cdot 6$ & $1 \cdot 7$ & $2 \cdot 1$ & $1 \cdot 0$ & $1 \cdot 6$ \\
\hline $140-239$ & $\mathrm{O}$ & 152 & 188 & 139 & 164 & 491 \\
\hline Neoplasms & $\mathrm{O} / \mathrm{E}$ & $3 \cdot 4^{\star}$ & $1 \cdot 5^{\star}$ & $1 \cdot 1$ & $1 \cdot 2$ & $1 \cdot 3 \star$ \\
\hline $240-279$ & $\mathrm{O}$ & 3 & 6 & 11 & 9 & 26 \\
\hline \multicolumn{7}{|l|}{ Endocrine, nutritional, metabolic \& } \\
\hline $\begin{array}{l}\text { 1mmunological diseases } \\
280-289\end{array}$ & $\begin{array}{l}\mathrm{O} / \mathrm{E} \\
\mathrm{O}\end{array}$ & $\begin{array}{l}1 \cdot 5 \\
0\end{array}$ & $\begin{array}{l}1 \cdot 1 \\
3\end{array}$ & $\begin{array}{l}1 \cdot 1 \\
4\end{array}$ & $\begin{array}{l}0 \cdot 9 \\
3\end{array}$ & 10 \\
\hline Blood \& blood forming diseases & $\mathrm{O} / \mathrm{E}$ & - & $2 \cdot 4$ & $2 \cdot 5$ & $1 \cdot 5$ & $2 \cdot 1$ \\
\hline $290-319$ & $\mathrm{O}$ & 1 & 1 & 9 & 9 & 19 \\
\hline Mental disorders & $\mathrm{O} / \mathrm{E}$ & 0.9 & $0 \cdot 3$ & $1 \cdot 5$ & 0.9 & $1 \cdot 0$ \\
\hline $320-389$ & $\mathrm{O}$ & 0 & 11 & 9 & 12 & 32 \\
\hline Nervous system \& sense organ diseases & $\mathrm{O} / \mathrm{E}$ & - & 1.8 & $1 \cdot 2$ & $1 \cdot 3$ & $1 \cdot 4$ \\
\hline $390-439$ & $\mathrm{O}$ & 131 & 295 & 291 & 233 & 819 \\
\hline Circulatory diseases & $\mathrm{O} / \mathrm{E}$ & $1 \cdot 3^{\star}$ & $1 \cdot 1$ & $1 \cdot 1$ & 0.9 & $1 \cdot 0$ \\
\hline $460-519$ & $\mathrm{O}$ & 40 & 77 & 68 & 57 & 202 \\
\hline Respiratory diseases & $\mathrm{O} / \mathrm{E}$ & $1 \cdot 4^{\star}$ & $1 \cdot 0$ & $1 \cdot 0$ & 1.0 & $1 \cdot 0$ \\
\hline $520-579$ & $\mathrm{O}$ & 33 & 54 & 40 & 36 & 130 \\
\hline Digestive diseases & $\mathrm{O} / \mathrm{E}$ & $6 \cdot 2^{\star}$ & $3 \cdot 5^{\star}$ & $2 \cdot 6^{\star}$ & $2 \cdot 2^{\star}$ & $2 \cdot 8^{\star}$ \\
\hline $580-629$ & $\mathrm{O}$ & 8 & 24 & 11 & 8 & 43 \\
\hline Genitourinary diseases & $\mathrm{O} / \mathrm{E}$ & $3 \cdot 1^{\star}$ & $3 \cdot 2^{\star}$ & $1 \cdot 5$ & $1 \cdot 2$ & $2 \cdot 0^{\star}$ \\
\hline $680-709$ & $\mathrm{O}$ & 0 & 1 & 0 & 0 & \\
\hline Skin \& subcutaneous tissue diseases & $\mathrm{O} / \mathrm{E}$ & - & $1 \cdot 8$ & - & - & 0.6 \\
\hline $710-739$ & $\mathrm{O}$ & 2 & 6 & 5 & 4 & 15 \\
\hline Musculoskeletal diseases & $\mathrm{O} / \mathrm{E}$ & $2 \cdot 1$ & $2 \cdot 2$ & $1 \cdot 5$ & $0 \cdot 7$ & $1 \cdot 4$ \\
\hline $740-759$ & $\mathrm{O}$ & 0 & 1 & 1 & 0 & 2 \\
\hline Congenital anomalies & $\mathrm{O} / \mathrm{E}$ & - & $1 \cdot 7$ & $1 \cdot 5$ & - & $1 \cdot 1$ \\
\hline $760-799$ & 0 & 0 & 1 & 4 & 2 & 7 \\
\hline Symptoms & $\mathrm{O} / \mathrm{E}$ & - & $0 \cdot 8$ & $3 \cdot 1$ & $1 \cdot 1$ & 1.6 \\
\hline $800-999$ & $\mathrm{O}$ & 14 & 18 & 16 & 13 & 47 \\
\hline Injury \& poisoning & $\mathrm{O} / \mathrm{E}$ & $2 \cdot 6^{\star}$ & $1 \cdot 2$ & $1 \cdot 1$ & $1 \cdot 0$ & $1 \cdot 1$ \\
\hline Total & $\mathrm{O}$ & 385 & 689 & 612 & 552 & 1853 \\
\hline & $\mathrm{O} / \mathrm{E}$ & $1 \cdot 9 \star$ & $1 \cdot 3^{\star}$ & $1 \cdot 2^{\star}$ & $1 \cdot 0$ & $1 \cdot 2^{\star}$ \\
\hline
\end{tabular}

^Statistically significant $(\mathrm{p}<0.05)$

TABLE III Observed numbers of deaths $(O)$ and observed to expected $(O / E)$ ratios for selected ICD rubrics

\begin{tabular}{|c|c|c|c|c|c|c|}
\hline \multirow[t]{2}{*}{ ICD rubric } & & \multicolumn{5}{|c|}{ Study years } \\
\hline & & 1 & $2-4$ & $5-7$ & $8-10$ & $2-10$ \\
\hline $\begin{array}{l}150 \\
\text { Malignant neoplasm oesophagus } \\
151 \\
\text { Malignant neoplasm stomach } \\
153 / 4 \\
\text { Malignant neoplasm colon, rectum } \\
162 \\
\text { Malignant neoplasm trachea, bronchus, } \\
\text { lung } \\
174 \\
\text { Malignant neoplasm female breast } \\
200-8 \\
\text { Lymphomas, myelomas, leukaemias } \\
410-4 \\
\text { Ischaemic heart disease } \\
430-8 \\
\text { Cerebrovascular disease } \\
530-7,578 \\
\text { Diseases of the oesophagus, stomach, } \\
\text { and duodenum: gastrointestinal } \\
\text { bleeding } \\
571 \\
\text { Chronic liver disease \& cirrhosis } \\
580-599 \\
\text { Urinary system disease }\end{array}$ & $\begin{array}{l}\mathrm{O} \\
\mathrm{O} / \mathrm{E} \\
\mathrm{O} \\
\mathrm{O} / \mathrm{E} \\
\mathrm{O} \\
\mathrm{O} / \mathrm{E} \\
\mathrm{O} \\
\\
\mathrm{O} / \mathrm{E} \\
\mathrm{O} \\
\mathrm{O} / \mathrm{E} \\
\mathrm{O} \\
\mathrm{O} / \mathrm{E} \\
\mathrm{O} \\
\mathrm{O} / \mathrm{E} \\
\mathrm{O} \\
\mathrm{O} / \mathrm{E} \\
\mathrm{O}\end{array}$ & $\begin{array}{l}7 \\
5 \cdot 4^{\star} \\
45 \\
10 \cdot 7^{\star} \\
15 \\
2 \cdot 7^{\star} \\
35 \\
2 \cdot 4^{\star} \\
5 \\
2 \cdot 0 \\
15 \\
6 \cdot 0^{\star} \\
81 \\
1 \cdot 3^{\star} \\
14 \\
0 \cdot 6 \\
12\end{array}$ & $\begin{array}{c}7 \\
1 \cdot 8 \\
26 \\
2 \cdot 3^{\star} \\
22 \\
1 \cdot 4 \\
69 \\
1 \cdot 7^{\star} \\
9 \\
1 \cdot 1 \\
16 \\
2 \cdot 3^{\star} \\
176 \\
1 \cdot 1 \\
58 \\
0 \cdot 9 \\
28\end{array}$ & $\begin{array}{c}10 \\
2 \cdot 3^{\star} \\
10 \\
1 \cdot 0 \\
12 \\
0 \cdot 8 \\
41 \\
1 \cdot 1 \\
10 \\
1 \cdot 1 \\
8 \\
1 \cdot 0 \\
171 \\
1 \cdot 1 \\
70 \\
1 \cdot 1 \\
18\end{array}$ & $\begin{array}{c}1 \cdot 7^{\star} \\
3 \\
0 \cdot 3 \\
6 \\
0 \cdot 7 \\
142 \\
0 \cdot 9 \\
61 \\
1 \cdot 0 \\
13\end{array}$ & $\begin{array}{c}1 \cdot 5 \star \\
22 \\
0 \cdot 8 \\
30 \\
1 \cdot 3 \\
489 \\
1 \cdot 0 \\
189 \\
1 \cdot 0 \\
59\end{array}$ \\
\hline
\end{tabular}

$\star$ Statistically significant $(\mathrm{p}<0.05)$ for the longevity of the individuals concerned despite the many and varied diseases coexisting with their digestive problems.

\section{CHRONIC LIVER DISEASE AND CIRRHOSIS (ICD 57 I)}

(Years 2-10-male obs 10, $\exp 4 \cdot 5$ : female obs 14 , $\exp 2 \cdot 3$ )

The disease was well established in 18 patients ( 12 were heavy users of alcohol) before cimetidine was started. Three of these were taking cimetidine and two ranitidine within six months of death. Two other patients diagnosed three years and one year after stopping cimetidine died of chronic active hepatitis and biliary cirrhosis respectively. We have no information concerning the remaining four deaths but it seems that the oesophageal and gastric lesions and abdominal pain accompanying liver disease (and alcohol abuse) attract prescriptions for cimetidine and associate the drug with the diease.

\section{PANCREATITIS (ICD 577)}

(Years 2-10-male obs 6, $\exp 1 \cdot 4$ : female obs nil, $\exp 1 \cdot 0)$

The excess of deaths in men was just statistically significant. The disease was associated with alcohol (in at least 2), duodenal ulcer (1), gall stones (1), and trauma (1). Of these five patients, three had not used cimetidine for at least six years before the onset of pancreatitis and two already had the disease when the drug was first prescribed. The sixth patient was a man aged 87 who was on maintenance cimetidine when admitted to hospital with terminal acute pancreatitis. He had taken cimetidine for at least six of the previous nine years but his drug history over the last three years was incomplete.

\section{DISEASES OF THE NERVOUS SYSTEM (ICD 320-389)}

(Years 2-10-male obs 19, exp 15: female obs 13, $\exp 10)$

The 32 deaths in this group comprise: pneumococcal meningitis (2), Parkinson's disease (7), Alzheimer's disease (2), motor neurone disease (MND) (8), multiple sclerosis (MS) (4), hemiplegia (6), cerebral palsy (1), pseudobulbar palsy (1), peripheral neuropathy of unknown cause (1).

The deaths from Parkinson's disease were unremarkable. Three of the $4 \mathrm{MS}$ patients had the disease before starting cimetidine and most of the other causes of death were associated with cerebrovascular disease. MND deaths were just significantly in excess (obs/exp 2.6), although small in number; one of these deaths was apparently misreported as being from MND (actually myelopathy due to severe cervical spondylosis) on the death certificate. One MND patient died aged 45 years. The diagnoses were all confirmed by neurologists and death occurred within 11-35 months. Two patients had probably stopped taking cimetidine two and four years before diagnosis of the disease, while five patients had taken many courses over several years before receptor antagonist before death (three of these had only stopped within a few days of their fatal illness) while 13 were taking cimetidine and six were taking ranitidine, mainly at maintenance levels, before death. There was nothing remarkable about deaths in this group except perhaps 
diagnosis. Two of these were virtually continuous courses but one patient was changed to ranitidine for three years before diagnosis. The 81 year old man with peripheral neuropathy recorded as the cause of death had also taken many courses of cimetidine but a large necrotic tumour had been removed from his bladder four months before the onset of symptoms.

The two deaths attributed to Alzheimer's disease occurred in men aged 82 and 73 years. There was no mention of the disease in the medical records and it was a doubtful diagnosis. There were three other mentions of Alzheimer's disease (not as the cause of death) on death certificates in years $2-10$ but these numbers are not excessive and again two of these were doubtful diagnoses in elderly patients. Presenile dementia (ICD 290.1) is a rubric sometimes used for patients with Alzheimer's disease but there were no deaths attributed to this cause. In years 2-10, we recorded three patients with presenile dementia mentioned on the death certificate; in at least two of these the disease was probably cerebrovascular in origin.

\section{USE OF $\mathrm{H}_{2}$ RECEPTOR ANTAGONISTS}

The simple questionnaire $(n=690)$ sent to GPs showed that $20 \%$ of the subjects in our surviving cohort sample were using cimetidine in 1987, which was $9 \%$ less than in 1984 . The use of ranitidine increased $8 \%$ from 1984 so that $15 \%$ of our sample were using this drug in 1987. The use of antisecretory drugs other than cimetidine and ranitidine was uncommon (around $1 \%$ ). Of those using cimetidine, $41 \%$ received prescriptions in all quarters of the year and $27 \%$ in only one quarter. In the three centres for which information was available (Nottingham, Oxford, and Portsmouth), by years 8,9 , and 10 , a constant $22 \%$ of those dying each year had used ranitidine in the past.

We looked at the diseases from which patients taking cimetidine in the last six months, last year, and last two years had died and compared them with patients who had not taken cimetidine in the three years before death. We could find no important differences. Neither was there any disease that was significantly associated with higher than usual prescription levels although, because of small numbers of deaths from some diseases, analysis was not always possible.

OTHER DIAGNOSES ON THE DEATH CERTIFICATE We used the newly available data (for 1985) from the OPCS to look for any excesses among secondary diagnoses appearing on the death certificate in years 2-9. Even with eight years' combined data, we could not find anything of importance to add to our UCD analysis (UCD is, of course, a major component of 'all diagnoses' data). We have the impression that rheumatoid arthritis influenced the life span of some of our subjects, but over a period of years, the disease was only mentioned on death certificates 25 times, giving an obs/exp ratio of $2 \cdot 2$. The ratios for diabetes mellitus (obs/exp 0.8), senile dementia (obs/exp 0.9), hypertension (obs/exp $0 \cdot 8$ ) and emphysema (male obs/exp $0 \cdot 2$ ) were less than unity while those for peripheral vascular disease (male obs/exp 1.5), chronic bronchitis (male obs/exp 1.3), and renal failure (obs/exp 1.6) were raised. Although peripheral vascular disease and chronic bronchitis had raised ratios, the numbers were very small and these results could have arisen by chance. We could find no excesses among other circulatory diseases (including cerebrovascular disease) or respiratory diseases (including chronic obstructive airways disease). Lung cancer and oesophageal cancer remain the only smoking related diseases showing a significant excess of deaths in the study.

\section{Discussion}

We have given brief clinical details of some cases in this and earlier reports mainly to illustrate the difference between the overall statistical findings and the reality when the age of the patient, the presence of other pathology, use of alcohol and tobacco and patterns of cimetidine prescription are taken into account.

The overall results of the study remain reassuring. In our first mortality report, ${ }^{3}$ we noted that cimetidine was being given, knowingly or unknowingly, in the late stages of many diseases and also to counter the adverse gastric effects of other drugs used in the treatment of serious disorders. This finding was underlined by the steady fall in the excess death rate in our second mortality report ${ }^{4}$ and is further stressed by the 10 year results reported here. Only deaths from oesophageal cancer, lung cancer, certain digestive system disorders, and liver disease have remained significantly in excess of expectation during years 5-10 of follow up.

Deaths from oesophageal (and gastric) cancer have been considered in detail in a recent report from our group. ${ }^{2}$ We were unable to discover evidence of a causal relationship between cimetidine use and the risk of oesophageal or gastric cancer, a conclusion also reached by La Vecchia et $a l^{6}$ in a case-control study of gastric cancer conducted in Italy and by Moller et al in a large cohort study conducted in Denmark ${ }^{7}$ (see below).

Lung cancer deaths continue to occur in excess of expectation in our cohort. This result is presumably attributable to the influence of cigarette smoking, although our earlier questionnaire study provided little evidence of excess smoking in the cimetidine cohort. Furthermore, deaths from other smoking related diseases (save for oesophageal cancer) are not in excess in the cohort. The association between cigarette smoking and lung cancer is very strong, however, and the relatively crude information obtained in our earlier questionnaire could easily have slightly underestimated smoking habits. Quite apart from this possibility, the published reports give some indication of an association between peptic ulcer and lung cancer in the precimetidine era. Bonnevie ${ }^{8}$ lists lung cancer, bronchitis, and emphysema; hepatic cirrhosis; and pancreatic cancer as statistically significant disease associations with peptic ulcer. In a review of published reports (precimetidine), Langman et al state that ulcer is probably unusually frequent in patients undergoing treatment for chronic renal failure and is possibly more frequent in 
association with cirrhosis, cardiovascular, and chronic respiratory disease. Ross et al ${ }^{10}$ claimed to have found an excess of deaths from smoking related diseases associated with peptic ulcer surgery, but only the association with lung cancer was statistically significant. Also of interest is the fact that Moller $e t a l^{7}$ in a follow up study of 16739 patients treated with cimetidine between 1977 and 1981 in Denmark, observed a relative risk of $1.5-2.0$ for cancer of the respiratory organs with no evidence of latency, indicating 'that there are common risk factors for peptic ulcer and for lung cancer'.

The excess of deaths from certain digestive disorders and from chronic liver disease and cirrhosis has followed the same pattern as in our last report and is attributable to the characteristics of the patients receiving cimetidine rather than to any adverse effect of the drug itself. It is notable that, even for these diseases, the observed to expected ratios have declined during the study from 6.3 in year 1 to 2.3 in years $8-10$ for disorders of the oesophagus, stomach, etc. and from $17 \cdot 3$ in year 1 to 3.3 in years $8-10$ for chronic liver disease. Likewise, the excess of deaths from pancreatitis in men seems to be related to alcohol misuse and to symptoms of the disease itself attracting prescriptions for cimetidine rather than to any more sinister factor.

Of the diseases of the nervous system, only the findings for MND are of interest, but one of the eight deaths was miscoded and the observed to expected ratio for years $2-10$ of 2.6 is of only borderline statistical significance. Nonetheless in most cases, there was a clear history of long term use of cimetidine and this observation might warrant further study. The relevance, if any, of a recent study of xenobiotic metabolism in patients with MND is uncertain. ${ }^{11}$

We also recorded two deaths from Alzheimer's disease in the nervous system group. Unfortunately, death certificate data regarding Alzheimer's disease are very imprecise. Presenile dementia is sometimes used as a pseudonym, the disease tends to be reported as senile dementia as the patient ages, and the term Alzheimer's disease is sometimes used to avoid the stigma of dementia. Nevertheless, members of our cohort have presumably taken large amounts of aluminium containing antacids and there is no excess of deaths from Alzheimer's disease or any of the dementias or any excess of these diseases mentioned in other parts of the death certificate. ${ }^{12}$ In conclusion, this study provides reassuring findings in a large cohort of cimetidine users after 10 years of follow up. We expect to continue to monitor mortality up to year 15 .

We thank Mr T Lucas, who organised and monitored the study and conducted the fieldwork in Oxfordshire; Mrs M Edmond and Mrs S Wood, who conducted the fieldwork in Nottingham an Portsmouth, respectively; Mr J Beresford and Mrs P de Rivaz who managed the computing; and Mrs D Collinge, who provided secretarial services. Dr A Flind and Dr J Barnard gave help and advice. We also thank the many general practitioners in the fou areas for their continued support. The NHS Central Registry, Family Health Service Authorities, and hospital records staff have also given invaluable cooperation. The study was supported by a grant from SmithKline Beecham.

1 Colin-Jones DG, Langman MJS, Lawson DH, Vessey MP. Cimetidine use and gastric cancer: a preliminary report from a postmarketing surveillance study. $B M \mathcal{F}$ 1982; 285: 13113.

2 Colin-Jones DG, Langman MJS, Lawson DH, Logan RFA, Paterson KR, Vessey MP. Post-cimetidine surveillance for up to ten years: incidence of carcinoma of the stomach and oesophagus. Qf Med 1991; 285: 13-9.

3 Colin-Jones DG, Langman MJS, Lawson DH, Vessey MP. Postmarketing surveillance of the safety of cimetidine: 12 month mortality report. $B M \mathcal{F} 1983 ; 286$ : 1713-6.

4 Colin-Jones DG, Langman MJS, Lawson DH, Vessey MP. Postmarketing surveillance of the safety of cimetidine: mortality during second,

5 Colin-Jones DG, Langman MJS, Lawson DH, Vessey MP. Postmarketing surveillance of the safety of cimetidine: 12 month morbidity report. $Q \mathcal{F}$ Med $1985 ; 54: 253-68$.

$6 \mathrm{La}$ Vecchia C, Negri E, D'Avanzo B, Franceschi S. Histamine-2-receptor antagonists and gastric cancer risk. Lance 1990; 336: 355-7.

7 Moller H, Lindvig K, Klefter R, Mosbech J, Jensen OM Cancer occurrence in a cohort of patients treated with cimetidine. Gut 1989; 30: 1558-62.

8 Bonnevie $\mathrm{O}$, Causes of death in duodenal and gastric ulcer. Gastroenterology 1977; 73: 1000-4

9 Langman MJS, Cooke AR. Gastric and duodenal ulcer and their associated diseases. Lancet 1976; i: 680-3.

10 Ross AHM, Smith MA, Anderson JR, Small WP. Late mortality after surgery for peptic ulcer. $N \mathrm{Engl} F \mathrm{Med} 1982$ 307: $519-22$.

11 Steventon G, Williams AC, Waring RH, Pall HS, Adams D. Xenobiotic metabolism in motorneurone disease. Lancet 1988; ii: 644-7.

12 Colin-Jones DG, Langman MJS, Lawson DH, Vessey MP. Alzheimer's disease in antacid users. Lancet 1989; 334: 1453 . 